\title{
Bladder management, severity of injury and period of latency: a descriptive study on 135 patients with spinal cord injury and bladder cancer
}

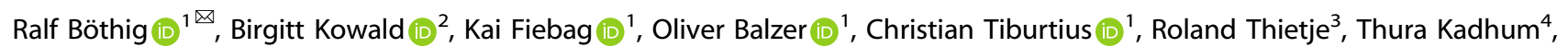 \\ German-speaking Medical SCI Society (DMGP) Bladder Cancer Extended Working Group* and Klaus Golka (iD) ${ }^{5}$
}

(c) The Author(s), under exclusive licence to International Spinal Cord Society 2021

\begin{abstract}
STUDY DESIGN: Longitudinal study.
OBJECTIVES: To describe the severity of spinal cord injury/disease (SCI/D), type and management of neurogenic lower urinary tract dysfunction, tumor characteristics, and bladder cancer latency period in SCI/D patients.

SETTING: Spinal cord injury centers in Germany, Austria, and Switzerland.

METHODS: Data of SCI/D patients diagnosed with bladder cancer were collected between Jan 2012-Dec 2019 in the course of annual surveys in the neuro-urological departments of all 28 centers. Demographic and paralysis-specific data, data on the type and management of neurogenic lower urinary tract dysfunction, and histopathological tumor characteristics were collected.

RESULTS: Regarding histopathological tumor characteristics, no significant differences were found in 135 individuals with SCI/D when stratified for bladder management without chronic catheterization, SCI/D severity, and ASIA classification. The mean latency period between the onset of SCI/D and the diagnosis of bladder cancer was significantly longer in patients with catheter-free emptying methods compared to patients with intermittent catheterization, and in patients with LMNL (Lower Motor Neuron Lesion) compared to patients with UMNL (Upper Motor Neuron Lesion).
\end{abstract}

CONCLUSIONS: Urinary bladder carcinomas are late events in the long-term course of SCl/D. Follow-up and approaches to screening must therefore be intensified with increasing duration of long-term SCl.

Spinal Cord (2021) 59:971-977; https://doi.org/10.1038/s41393-021-00651-3

\section{INTRODUCTION}

Worldwide, bladder cancer is the 10th most common form of cancer, with an estimated 549,000 new cases and 200,000 deaths in 2018. The incidence and mortality rates are estimated at 9.6 and 3.2 for men and 2.4 and 0.9 per 100,000 for women. Men are thus affected about 4 times more often than women [1].

According to a current estimate, 25-30 million people worldwide live with spinal cord injury/disease (SCI/D); the annual incidence (2016) worldwide is almost one million new cases [2]. Due to medical progress, the life expectancy of persons with SCI/D has improved dramatically in recent decades [3]. Thus, cancer is currently the third most cause of death in individuals with $S C \mathrm{Cl} D$, and bladder cancer is the second most common tumor after lung cancer [4].

Against this background, the question of a possible causal relationship between $\mathrm{SCl} / \mathrm{D}$ and the occurrence of bladder cancer has gained much interest in recent years. Due to incoherent data, the question of the incidence of bladder cancer in SCl/D patients has long been unclear. Two systematic reviews covering data from 1966 to
2007 [5] and from 1963 to 2014 [6] have recently calculated a "pooled incidence rate" which is at $0.33 \%$ and $0.60 \%$, respectively.

Several studies in recent years have consistently identified the following special features in patients with SCI/D and bladder cancer [7]: Bladder cancer in patients with $\mathrm{SCl} / \mathrm{D}$ is usually diagnosed one to two decades earlier than in the general population, it is characterized by a more advanced stage of the primary tumor (higher T category) and it is a more aggressive disease. The same unfavorable tumor characteristics and the earlier onset of the disease were previously reported in SCI/D patients treated without permanent indwelling catheters [8]. The aforementioned tumor characteristics lead to a 6.7fold higher bladder cancer mortality rate in people with SCI/D compared to the general population [9], which increases with the duration of paralysis [9].

Therefore, bladder cancer in $\mathrm{SCl} / \mathrm{D}$ patients remains a challenge for clinicians particularly regarding timely diagnosis and for basic scientists in elucidating pathophysiological mechanisms. Especially in view of the often poor prognosis, an effective screening

\footnotetext{
'Department of Neuro-Urology, Centre for Spinal Cord Injuries, BG Klinikum Hamburg, Hamburg, Germany. ${ }^{2}$ Biomechanical Laboratory, BG Klinikum Hamburg, Hamburg, Germany. ${ }^{3}$ Centre for Spinal Cord Injuries, BG Klinikum Hamburg, Hamburg, Germany. ${ }^{4}$ Specialist Clinic for Psychosomatic Rehabilitation, Mittelrheinklinik, Boppard-Bad Salzig, Germany. ${ }^{5}$ Clinical Occupational Medicine, Leibniz Research Centre for Working Environment and Human Factors at TU Dortmund (IfADo), Dortmund, Germany. ${ }^{*} \mathrm{~A}$ list of authors and their affiliations appears at the end of the paper. ${ }^{\circledR}$ email: R.Boethig@bgk-hamburg.de
}

Received: 21 October 2020 Revised: 26 May 2021 Accepted: 27 May 2021

Published online: 17 June 2021 
strategy that is as little burdensome as possible and cost-effective is urgently needed. Unfortunately, such a strategy has not yet been established in the concept of lifelong surveillance of SCl/D patients [10]. Elliott [11] has clearly pointed out that at the current state of knowledge screening of individuals with $\mathrm{SCl} / \mathrm{D}$ for bladder cancer is not justified. It is of utmost importance to identify SCI/D subpopulations with a sufficiently high risk that would justify screening measures leading to better chances of survival and/or higher quality of life.

This paper aims to contribute to a better definition of a starting point for bladder cancer screening in SCI/D patients, to evaluate the possible influence of bladder management and type of bladder dysfunction on bladder cancer risk, and to elucidate a possible relationship between injury grade or ASIA classification and bladder cancer risk.

\section{METHODS}

Data of paraplegic patients with newly diagnosed histologically confirmed bladder cancer were collected between January 1st, 2012 and December 31 st, 2019 in the course of annual surveys. All 28 neuro-urological departments of the paraplegic centers in Germany, Austria, and Switzerland affiliated in the German-speaking Medical SCl Society (Deutschsprachige Medizinische Gesellschaft für Paraplegiologie, DMGP) participated in this study.

Demographic and paralysis-specific data on pre-existing $S C I / D$, data on the type and management of neurogenic lower urinary tract dysfunction (NLUTD), and all tumor characteristics (tumor type, T category, and grading) were collected entirely by an electronic questionnaire.

The study included all SCI/D patients presented to the participating departments as inpatient or outpatient within the study period, including 28 Hamburg patients previously published [8]. There was no specific screening strategy for urinary bladder tumors in the departments involved, so the tumors were diagnosed if they became symptomatic with hematuria, hydronephrosis, or frequently recurrent urinary tract infections or as incidental findings e.g., at diagnostics or treatment of complications or during regular "check-up" procedures (mostly sonographically or cystoscopically).

The neurological level of SCI/D was classified according to the International Standards for Neurological Classification of SCI (ISNCSCI) and the severity (degree of impairment) was classified in accordance with the American Spinal Injury Association (ASIA) Impairment Scale (AIS) [12]. Neurologic level of injury and severity of the SCI/D were categorized as follows: C1-4 AIS A, B, and C; C5-8 AIS A, B, and C; T1-S3 AIS A, B, and C; AIS $D$ at any injury level [13].

The type of bladder paralysis and assignment as UMNL (Upper Motor Neuron Lesion with detrusor overactivity) or LMNL (Lower Motor Neuron Lesion with areflexia or flaccid paralysis of the urinary bladder muscle) was confirmed by video-urodynamic examination in all patients included.

All bladder tumors were classified according to the WHO 2016 Classification of Tumors of the Urinary System [14]. For details, see Supplementary TNM Information.

The data were entered into a database and pseudonymized during entry. The data are presented as mean and standard deviation (SD) or median and $25 \%$ and $75 \%$ quartile, depending on the presence or absence of a normal distribution. The latter was tested by the Shapiro-Wilk-Test. Frequencies or proportions are reported as percentages with a $95 \%$ confidence interval $(\mathrm{Cl})$. Binomial confidence intervals were calculated using the Clopper-Pearson interval method. The post-hoc mean comparison was performed with the Tuckey test; the $95 \%$ confidence intervals of the differences were calculated. Statistical analyses were conducted using SAS 9.4 software (SAS Institute Inc., Cary, NC, USA).

All applicable institutional and governmental regulations concerning the ethical use of the data were observed. The ethics committee of the University of Lübeck (AZ 17-345A) and the Institutional Review Board (Institution for Statutory Accident Insurance and Prevention in the Health and Welfare Services, address: Pappelallee 33, 22089 Hamburg) both approved the study.

\section{RESULTS}

This study includes 135 individuals with SCI/D from 22 of the participating $28 \mathrm{SCl}$ centers in the German-speaking area (Suppl. Table 1). In 6 centers, no bladder cancer cases were observed during the study period. Baseline demographic data, SCI/D-related data, data on the type of bladder paralysis and bladder management, as well as tumor characterization data, are presented in Table 1.

Figure 1 shows the frequencies of the relevant tumor characteristics T category, grading, and tumor type stratified for the applied bladder management with and without intermittent catheterization. There were no evident differences between intermittent catheterization and the other bladder emptying methods (i.e., no catheter use)

Table 2 presents the frequencies of $T$ categories $(<T 2$ vs. $\geq T 2)$ and grading (G1, G2 vs. G3, G4) for urothelial carcinoma and squamous cell carcinoma stratified for bladder management with and without intermittent catheterization. No relevant differences were observed. All 4 patients with permanent suprapubic catheterization were not included in these descriptions. The characteristics of these four patients are given in Suppl. Table 2.

A comparison of the tumor characteristics T category, grading and tumor type with parameters for $\mathrm{SCl} / \mathrm{D}$ severity according to ISCoS recommendation is presented in Fig. 2. The comparison of neurologically complete with sensory incomplete SCI/D and a comparison of motor complete vs. motor incomplete $\mathrm{SCI} / \mathrm{D}$ is presented in Fig. 3. No evident differences were observed in both comparisons.

Next, the latency period between the onset of SCl/D and the diagnosis of bladder cancer is presented for the different methods of bladder emptying, the different types of bladder dysfunction, the severity of the injury, or the tumor characteristics (Tables 3 and 4). A comparison of latencies showed longer latencies for catheter-free bladder emptying types, for LMNL, for MIBC, and SCC. Regarding the level of paralysis, a difference was only found in the direct comparison between C1-C4 AIS A, B, C vs. T1-S5 AIS A, B, C: the shorter the latencies the higher the level of paralysis. The association between the latency period and the bladder emptying method or neurologic type of bladder paralysis is shown in boxplots in Suppl. Figure 1. Details of the 11 patients with LMNL, i. e., acontractile detrusor function, are shown in Suppl. Table 4.

The added-up duration of all SCI/D patients studied from the onset of spinal cord injury to the first diagnosis of bladder cancer, i.e., the addition of the latencies of each of the 135 patients investigated, was 4,229 years or 50,976 months. Forty of the 135 $\mathrm{SCl} / \mathrm{D}$ bladder cancer patients were reported to have been managed with indwelling catheters for a total of 3,839 months. This represents $7.53 \%$ of the added-up latency periods, i.e., 50,976 months, of all $135 \mathrm{SCl} / \mathrm{D}$ patients studied (Suppl. Table 3).

The database with all data of the described patients is available in pseudonymized form as a Suppl. Table 3.

\section{DISCUSSION}

This study is based on $135 \mathrm{SCl} / \mathrm{D}$ patients with bladder cancer identified during annual surveys from 2012 to 2019 in all SCI/D centers that are members of the "German-speaking Medical Society for Paraplegiology (DMGP)" in Germany, Austria, and Switzerland.

The data of this study, first of all, confirm the results of the previous monocentric Hamburg study on SCI/D patients, who were also managed almost entirely without chronic indwelling catheterization $[8,15]$. The average age of SCI/D patients at the time of initial bladder cancer diagnosis was about 20 years younger compared to the general population. The latency period between the onset of paralysis and bladder cancer diagnosis was 31.5 years and the proportion of muscle-invasive tumors (MIBC, T category $\geq T 2$ ) was $69 \%$. These results of this study on $S C l / D$ patients with urinary bladder cancer, who were almost exclusively managed without indwelling catheters, are comparable to the findings of the systematic review by Ismail et al. [6] and the metaanalysis by Gui-Zhong and Li-Bo [5], in which the proportion of $\mathrm{SCI} / \mathrm{D}$ patients managed with indwelling catheters varied between 
Table 1. Summary of medical findings and tumor characteristics in $\mathrm{SCl}$ patients with bladder cancer.

\begin{tabular}{|c|c|c|}
\hline Parameter & Classification & $N(\%)$ \\
\hline Patients & & 135 \\
\hline \multirow[t]{2}{*}{ Gender } & Male & $105(77.8)$ \\
\hline & Female & $30(22.2)$ \\
\hline \multirow[t]{2}{*}{$\mathrm{SCl} / \mathrm{D}$} & Tetraplegia & $43(31.9)$ \\
\hline & Paraplegia & $92(68.1)$ \\
\hline \multirow[t]{4}{*}{ ASIA } & AIS A & $92(68.1)$ \\
\hline & AIS B & $16(11.9)$ \\
\hline & AIS C & $15(11.1)$ \\
\hline & AIS D & $12(8.9)$ \\
\hline \multirow[t]{4}{*}{ Severity } & C1 - C4, AIS A, B, C & $15(11.1)$ \\
\hline & C5 - C8, AIS A, B, C & $22(16.3)$ \\
\hline & T1 - S5, AIS A, B, C & $86(63.7)$ \\
\hline & All AIS D & $12(8.9)$ \\
\hline \multirow[t]{2}{*}{ NLUTD } & $\begin{array}{l}\text { Upper motor neuron } \\
\text { lesion (UMNL) }\end{array}$ & $124(91.9)$ \\
\hline & $\begin{array}{l}\text { Lower motor neuron } \\
\text { lesion (LMNL) }\end{array}$ & $11(8.1)$ \\
\hline \multirow[t]{7}{*}{$\begin{array}{l}\text { Bladder } \\
\text { management }\end{array}$} & $\begin{array}{l}\text { Intermittent self- } \\
\text { catheterization (ISC) }\end{array}$ & $44(32.6)$ \\
\hline & $\begin{array}{l}\text { Intermittent catheterization by } \\
\text { attendant (ICA) }\end{array}$ & $6(4.4)$ \\
\hline & Reflex voiding & $62(45.9)$ \\
\hline & SDAF/SARS & $5(3.7)$ \\
\hline & Straining & $7(5.2)$ \\
\hline & Volitional & $7(5.2)$ \\
\hline & Suprapubic catheter & $4(3.0)$ \\
\hline \multirow[t]{6}{*}{ Tumor type } & Urothelial carcinoma (UC) & $98(72.6)$ \\
\hline & $\begin{array}{l}\text { Squamous cell } \\
\text { carcinoma (SCC) }\end{array}$ & $31(23.0)$ \\
\hline & Adenocarcinoma & $2(1.5)$ \\
\hline & Sarcoma & $1(0.7)$ \\
\hline & Undifferentiated & $1(0.7)$ \\
\hline & Not specified & $2(1.5)$ \\
\hline \multirow[t]{6}{*}{ T category } & $\mathrm{Ta}$ & $23(17.0)$ \\
\hline & Tis & $3(2.2)$ \\
\hline & $\mathrm{T} 1$ & $16(11.9)$ \\
\hline & $\mathrm{T} 2$ & $31(23.0)$ \\
\hline & $\mathrm{T} 3$ & $36(26.7)$ \\
\hline & T4 & $26(19.3)$ \\
\hline \multirow[t]{5}{*}{ Grading } & G1 & $18(13.3)$ \\
\hline & G2 & $20(14.8)$ \\
\hline & G3 & $86(63.7)$ \\
\hline & G4 & $3(2.2)$ \\
\hline & No data available & $8(5.9)$ \\
\hline Age at $\mathrm{SCl}$ & $\begin{array}{l}\text { Years (median; 25\%/ } \\
75 \% \text {; range) }\end{array}$ & $\begin{array}{l}24 ; 17 / \\
34 ; 0-77\end{array}$ \\
\hline $\begin{array}{l}\text { Age at tumor } \\
\text { diagnosis }\end{array}$ & Years (mean; SD; range) & $\begin{array}{l}56.6 ; \\
11.6 ; 19-88\end{array}$ \\
\hline Latency & Years (mean; SD; range) & $\begin{array}{l}31.5 ; \\
13.5 ; 1-60\end{array}$ \\
\hline
\end{tabular}

NLUTD neurogenic lower urinary tract dysfunction, SDAF/SARS sacral deafferentation/sacral anterior root stimulation.

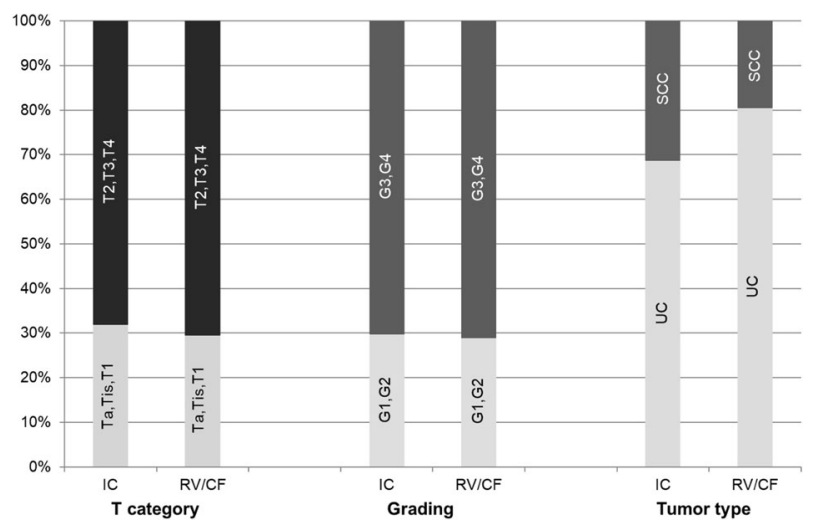

Fig. 1 Bladder management and T category, grading, and tumor type in $\mathrm{SCl}$ patients with bladder cancer. IC intermittent catheterization, i.e., intermittent self-catheterization (ISC, $n=44$ ) and intermittent catheterization by an attendant (ICA, $n=6$ ); RV/CF reflex voiding $(n=62)$ and other catheter-free voiding methods (SDAF/SARS $n=5$, straining $n=7$, volitional $n=7$ ); UC urothelial carcinoma, SCC squamous cell carcinoma.

$50-100 \%$ in the analyzed study group. However, only Ismail et al. [6] reported on the proportion of muscle-invasive bladder carcinoma which was $67.7 \%$. The high proportion of unfavorable grading $(65.9 \% \mathrm{G} 3$ or G4) of bladder cancer in the studied patients with $\mathrm{SCI} / \mathrm{D}$ is also consistent with the data from the Hamburg study $[8,15]$. Furthermore, the previously described observation [15] that bladder cancer occurs in both LMNL and UMNL has now been confirmed in this larger number of patients.

This study showed no differences in tumor characteristics stratified for the type of bladder emptying (intermittent catheterization or catheter-free emptying), the severity of the injury, or the neurological completeness of paraplegia. With regard to the latency period, however, there was evidence of a longer time interval between the onset of paralysis and the initial diagnosis of bladder cancer in patients applying catheter-free bladder emptying methods or patients with LMNL.

Bladder management by transurethral or suprapubic indwelling catheters is considered a proven risk factor for the development of bladder cancer in patients with spinal cord injury and in abledbodied patients as well [16]. According to a meta-analysis [17], about $1 \%$ of all SCI/D patients with bladder management with an indwelling bladder catheter developed bladder cancer in the long term. Several studies showed a significant increase in bladder cancer risk, which increased further with the increasing duration of permanent indwelling catheterization of the bladder [18, 19]. Kalisvaart et al. [20] were the first to report an increased bladder cancer risk in SCl/D patients managed without indwelling catheters, which indicates that the neurogenic bladder rather than the indwelling catheter may be the key risk factor for bladder cancer development. This finding was confirmed in the Hamburg study [8], which demonstrated for the first time in detail that the prognosis in these SCl/D bladder cancer patients managed without chronic suprapubic or indwelling catheterization was also poor.

In the present multicentre study, indwelling catheters played only a very minor role (only $7.53 \%$ of the added-up latency times of all patients included). This should be considered as a likely explanation for the relatively low proportion of patients with squamous cell carcinoma in this study compared to the studies published so far $[5,6]$. Furthermore, it is striking that in our large dataset the latency period is over 30 years. In previous analyses on $\mathrm{SCI} / \mathrm{D}$ cohorts with a large proportion of patients with permanent catheters, the median latency period was 24.9 years, based on 332 $\mathrm{SCl} / \mathrm{D}$ patients [6], and 24 years, based on $320 \mathrm{SCl} / \mathrm{D}$ patients [5], respectively. In any case, bladder cancer is a late event in the long- 
Table 2. Bladder management and tumor type, T category, and grading.

\begin{tabular}{|c|c|c|c|c|c|c|}
\hline & & & \multicolumn{2}{|l|}{ IC } & \multicolumn{2}{|l|}{$\mathrm{RV} / \mathrm{CF}$} \\
\hline & & & $N(\%)$ & $95 \% \mathrm{Cl}^{*}$ & $N(\%)$ & $95 \% \mathrm{Cl}^{*}$ \\
\hline Tumor type & & UC & $33(68.8)$ & $53.75 \%, 81.34 \%$ & $62(80.5)$ & $69.91 \%, 88.67 \%$ \\
\hline \multirow[t]{3}{*}{ UC/SCC/other } & T category & $\operatorname{NMIBC}(\mathrm{Ta}, \mathrm{Tis}, \mathrm{T} 1)$ & $16[32.0)$ & $19.52 \%, 46.70 \%$ & $24(29.6)$ & $19.99 \%, 40.81 \%$ \\
\hline & & $\operatorname{MIBC}(\mathrm{T} 2, \mathrm{~T} 3, \mathrm{~T} 4)$ & $34(68.0)$ & $53.30 \%, 80.48 \%$ & $57(70.4)$ & $59.19 \%, 80.01 \%$ \\
\hline & Grading & G1, G2 & $14(29.8)$ & $17.34 \%, 44.89 \%$ & $22(28.9)$ & $19.11 \%, 40.49 \%$ \\
\hline \multirow[t]{4}{*}{ UC } & T category & $\operatorname{NMIBC}(\mathrm{Ta}, \mathrm{Tis}, \mathrm{T} 1)$ & $16(48.5)$ & $30.80 \%, 66.46 \%$ & $20(32.3)$ & $20.94 \%, 45.34 \%$ \\
\hline & & $\operatorname{MIBC}(\mathrm{T} 2, \mathrm{~T} 3, \mathrm{~T} 4)$ & $17(51.5)$ & $33.54 \%, 69.20 \%$ & $42(67.7)$ & $54.66 \%, 79.06 \%$ \\
\hline & Grading & $\mathrm{G} 1, \mathrm{G} 2$ & $12(36.4)$ & $20.40 \%, 54.88 \%$ & $12(20.0)$ & $10.78 \%, 32.33 \%$ \\
\hline & & G3, G4 & $21(63.6)$ & $45.12 \%, 79.60 \%$ & $48(80.0)$ & $67.67 \%, 89.22 \%$ \\
\hline SCC & $\mathrm{T}$ category & $\operatorname{NMIBC}(\mathrm{Ta}, \mathrm{Tis}, \mathrm{T} 1)$ & $0(0.0)$ & $00.00 \%, 21.80 \%$ & $2(13.3)$ & $1.66 \%, 40.46 \%$ \\
\hline
\end{tabular}

IC intermittent catheterization, i.e., intermittent self-catheterization (ISC, $n=44$ ) and intermittent catheterization by an attendant (ICA, $n=6$ ), RV/CF reflex voiding $(n=62)$ and other catheter-free voiding methods (SDAF/SARS $n=5$, straining $n=7$, volitional $n=7$ ), UC urothelial carcinoma, SCC squamous cell carcinoma, NMIBC non-muscle invasive bladder cancer, $M I B C$ muscle invasive bladder cancer. ${ }^{*} \mathrm{Cl}$ 's obtained using Clopper-Pearson method.

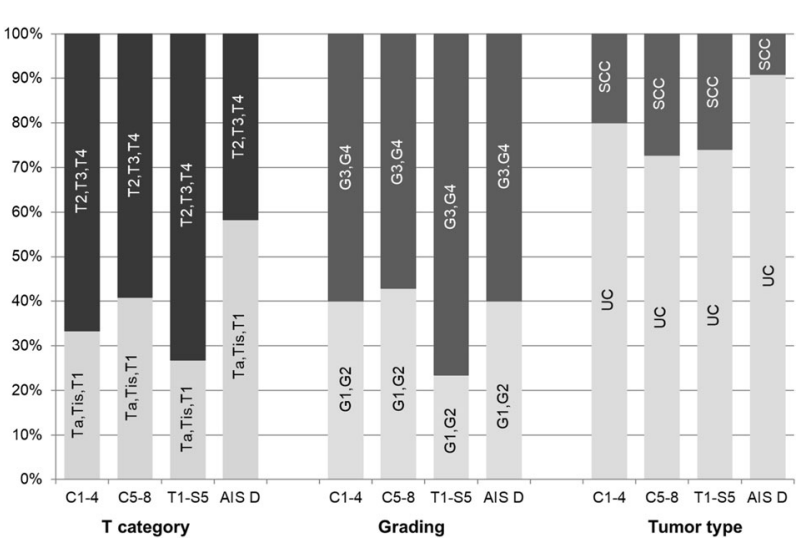

Fig. 2 Severity of injury and T category, grading, and tumor type in SCI patients with bladder cancer. UC urothelial carcinoma, SCC squamous cell carcinoma.

term course of SCI/D. Follow-up and screening approaches must therefore be intensified with increasing duration $\mathrm{SCl} / \mathrm{D}$.

It is therefore important to clarify the question of whether different tumor characteristics can be detected in permanent catheter-free $\mathrm{SCl} /$ $D$ patients with bladder cancer depending on the method of bladder emptying (intermittent catheterization or catheter-free emptying) or depending on different SCI/D parameters (level and severity of the neurological lesion, UMNL or LMNL), which could possibly provide clues for individual screening approaches.

In contrast to incidental bladder cancer observed at the first urological work-up after the onset of SCI/D [21], the prognosis of bladder cancer in long-term SCl/D patients $[5,6]$ is poor. This is also true for SCl/D patients with permanent catheter-free bladder management [8]. Against this background, the question of meaningful screening of this population is a high priority. Unfortunately, neither a systematic review on urological follow-up recommendations for SCl/D patients [10], nor a recent systematic review on the value of cystoscopy and cytology for early detection of bladder cancer in patients with neurogenic bladder [22], nor the current EAU

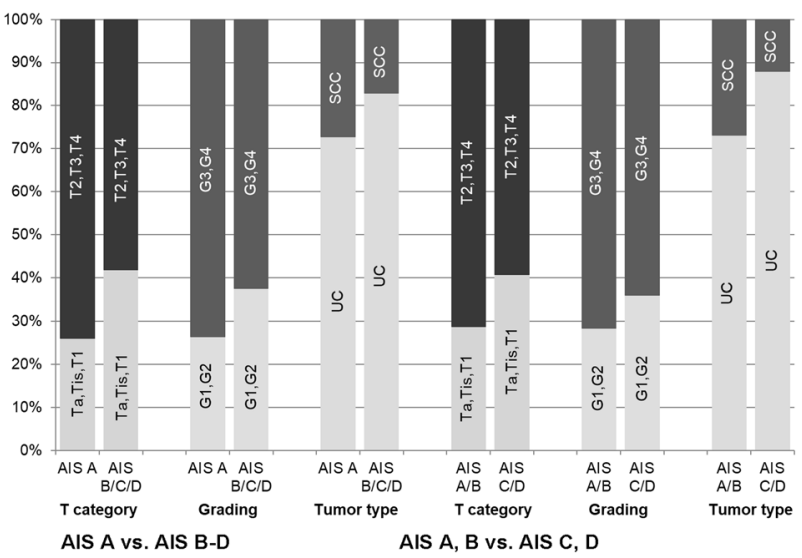

Fig. 3 Left: $T$ category, grading and tumor type in neurologically complete (AIS A) vs. sensory incomplete (AIS B, C, D) SCI/D and Right: Motor complete (AIS A, B) vs. motor incomplete (AIS C, D) SCI/D. UC urothelial carcinoma, SCC squamous cell carcinoma.

neuro-urology guideline [23] provides recommendations for screening for bladder cancer in patients with NLUTD. In their guidelines, the Paralyzed Veterans of America recommend conducting more frequent cystoscopic evaluations in individuals with chronic indwelling catheters than for those with nonindwelling methods of bladder management [24].

What may the results of the present descriptive study contribute to this problem? Overall, the evidence of the results is certainly limited due to the study design, and thus the conclusions should be viewed with caution. Nevertheless, the results can be interpreted in such a way that in $\mathrm{SCI} / \mathrm{D}$ patients without indwelling catheters neither the level or the severity of the spinal cord lesion nor the method of bladder emptying (intermittent catheterization or catheter-free emptying) noticeably affects $T$ category, grading, and tumor entity of the urinary bladder cancer. Thus, the aforementioned parameters are not suitable to define particularly vulnerable subpopulations for which screening measures would be more justified. 
Table 3. Latency period between spinal cord injury and bladder cancer diagnosis.

\begin{tabular}{|c|c|c|c|c|}
\hline Parameter & Classification & $N$ & Latency period in years (mean; SD; range) & $95 \% \mathrm{Cl}$ \\
\hline \multirow[t]{3}{*}{ Bladder management } & IC & 50 & $27.8 ; 12.9 ; 3-57$ & $24.11-31.41$ \\
\hline & $\mathrm{RV} / \mathrm{CF}$ & 81 & $34.9 ; 12.4 ; 4-60$ & $32.14-37.61$ \\
\hline & SPC & 4 & & \\
\hline \multirow[t]{2}{*}{ NLUTD } & UMNL & 124 & $30.6 ; 13.3 ; 1-60$ & $28.27-32.99$ \\
\hline & LMNL & 11 & $40.9 ; 13.2 ; 16-57$ & $32.05-49.77$ \\
\hline \multirow[t]{3}{*}{ Severity } & C1-4, AIS A, B, C & 15 & $23.1 ; 12.4 ; 1-42$ & $16.25-30.01$ \\
\hline & T1-S5, AIS A, B, C & 86 & $33.6 ; 12.6 ; 3-57$ & $30.87-36.27$ \\
\hline & All AIS D & 12 & $29.8 ; 14.1 ; 7-47$ & $20.80-38.70$ \\
\hline \multirow[t]{2}{*}{ T category } & NMIBC ( $\mathrm{Ta}, \mathrm{Tis}, \mathrm{T} 1)$ & 42 & $26.9 ; 15.1 ; 2-57$ & $22.14-31.57$ \\
\hline & $\operatorname{MIBC}(T 2, T 3, T 4)$ & 93 & $33.5 ; 12.2 ; 1-60$ & $31.03-36.07$ \\
\hline Grading & G1, G2 & 38 & $29.8 ; 15.0 ; 2-52$ & $24.90-34.78$ \\
\hline Tumor type & Other* & 6 & & \\
\hline \multicolumn{5}{|c|}{$\begin{array}{l}\text { IC intermittent catheterization, i.e., intermittent self-catheterization (ISC, } n=44) \text { and intermittent catheterization by an attendant (ICA, } n=6), R V / C F \text { reflex } \\
\text { voiding ( } n=62) \text { and other catheter-free voiding methods (SDAF/SARS } n=5 \text {, straining } n=7 \text {, volitional } n=7), \text { SPC suprapubic catheter, NLUTD neurogenic } \\
\text { lower urinary tract dysfunction, UMNL upper motor neuron lesion, } L M N L \text { lower motor neuron lesion, NMIBC non-muscle invasive bladder cancer, MIBC muscle } \\
\text { invasive bladder cancer, UC urothelial carcinoma; SCC squamous cell carcinoma. } \\
{ }^{*} \text { Adenocarcinoma } n=2 \text {, sarcoma } n=1 \text {, undifferentiated } n=1 \text {, not specified } n=2 \text {. }\end{array}$} \\
\hline
\end{tabular}

Table 4. Latency period, post-hoc mean comparison of the differences.

\begin{tabular}{|c|c|c|c|c|}
\hline & & Difference of means & $95 \% \mathrm{Cl}$ & \\
\hline Bladder management & IC vs. RV/CF & -7.12 & -11.58 & -2.65 \\
\hline NLUTD & UMNL vs. LMNL & -10.28 & -18.53 & -2.03 \\
\hline \multirow[t]{5}{*}{ Severity } & $C 1-4 A, B, C$ vs. $C 5-8 A, B, C$ & -6.73 & -18.26 & 4.80 \\
\hline & C1-4 A,B,C vs. T1-S5 A,B,C & -10.44 & -20.07 & -0.80 \\
\hline & C1-4 $A, B, C$ vs. all AIS D & -6.62 & -19.95 & 6.72 \\
\hline & C5-8 A,B,C vs. T1-S5 A,B,C & -3.71 & -11.93 & 4.52 \\
\hline & T1-S5 A,B,C vs. all AIS D & 3.82 & -6.80 & 14.43 \\
\hline T category & NMIBC vs. MIBC & -6.69 & -11.54 & -1.84 \\
\hline Grading & $\mathrm{G} 1, \mathrm{G} 2$ vs. G3,G4 & -1.73 & -6.90 & 3.44 \\
\hline Tumor type & UC vs. SCC & -6.57 & -12.05 & -1.08 \\
\hline
\end{tabular}

Comparisons that are significant at the 0.05 level are shown in bold.

IC intermittent catheterization, i.e., intermittent self-catheterization (ISC, $n=44)$ and intermittent catheterization by an attendant (ICA, $n=6), R V / C F$ reflex voiding $(n=62)$ and other catheter-free voiding methods (SDAF/SARS $n=5$, straining $n=7$, volitional $n=7$ ), NLUTD neurogenic lower urinary tract dysfunction, UMNL upper motor neuron lesion, $L M N L$ lower motor neuron lesion, NMIBC non-muscle invasive bladder cancer, MIBC muscle invasive bladder cancer, UC urothelial carcinoma, SCC squamous cell carcinoma.

On the other hand, analysis of the present multicentre dataset points to a longer latency in patients with completely catheterfree voiding methods and in patients with LMNL. This could be useful when establishing a timeline for bladder cancer screening.

To the best of our knowledge, this study comprises the largest published multicentre dataset of fully documented SCI/D-related findings, neuro-urological findings, and tumor characteristics of patients with SCI/D and bladder cancer, in addition to demographic data.

The longitudinal design of this study with annual surveys over a period of 8 years allows only limited conclusions for several reasons. The main shortcomings of this approach are the selection bias, the lack of an external control group, and no analysis on survival rates. In addition, information on various bladder cancer risk factors such as tobacco smoking, medical history of exposure to occupational carcinogens, frequency of urinary tract infections or asymptomatic bacteriuria, and the bacteria involved were not collected or analyzed. Another limitation of this study is that no systematic bladder cancer screening was performed, as there are currently no generally accepted recommendations in guidelines or in the literature.

Future studies with much larger numbers of patients are needed to clarify these complex issues. A direct comparison of SCI/D patients with chronic indwelling catheterization and catheter-free bladder management would be conclusive. Furthermore, it should be investigated on larger numbers of patients whether different tumor characteristics can also be observed between patients with UMNL and 
patients with LMNL. Also, the difference in latency of bladder cancer between SCI/D patients with high tetraplegia (C1-C4 AIS A, B, C) and paraplegia (T1-S5 AIS A, B, C) observed in this study should be confirmed in a larger patient population. In addition, it should be noted that the classification of SCl/D according to neurological grade and severity [13], which is established in many orthopedic and neurological aspects, has some limitations in the field of neurourology. For example, the neuro-urologically fundamental distinction between the consequences of upper or lower motor neuron lesion (UMNL or LMNL) has not yet been addressed in this classification and thus also in the design of many studies.

In summary, this study may represent another step towards identifying $\mathrm{SCl} / \mathrm{D}$ subpopulations at highly increased risk of bladder cancer who should be included in intensified screening programs in the long term to detect bladder cancer disease at earlier, more curable stages.

\section{DATA AVAILABILITY}

The datasets generated during and/or analyzed during this study are available from the corresponding author on reasonable request. An anonymized overview of the data of the patients in this study is given in Suppl. Table 3.

\section{REFERENCES}

1. Bray F, Ferlay J, Soerjomataram I, Siegel RL, Torre LA, Jemal A. Global cancer statistics 2018: GLOBOCAN estimates of incidence and mortality worldwide for 36 cancers in 185 countries [published correction appears in CA Cancer J Clin. 2020;70:313]. CA Cancer J Clin. 2018;68:394-424.

2. GBD 2016 Traumatic Brain Injury and Spinal Cord Injury Collaborators. Global, regional, and national burden of traumatic brain injury and spinal cord injury, 1990-2016: a systematic analysis for the Global Burden of Disease Study 2016. Lancet Neurol. 2019:56-87.

3. Savic G, DeVivo MJ, Frankel HL, Jamous MA, Soni BM, Charlifue S. Causes of death after traumatic spinal cord injury - a 70-year British study. Spinal Cord. 2017:55:891-7

4. National Spinal Cord Injury Statistical Center. University of Alabama at Birmingham, 2018 Annual Statistical Report - Complete Public Version. https://www.sciinfo-pages.com/wp-content/media/NSCISC-2018-Annual-Report.pdf (Last accessed 15 March 2021).

5. Gui-Zhong L, Li-Bo M. Bladder cancer in individuals with spinal cord injuries: a meta-analysis. Spinal Cord. 2017;55:341-5.

6. Ismail S, Karsenty G, Chartier-Kastler E, Cussenot O, Compérat E, Rouprêt M, et al. Prevalence, management, and prognosis of bladder cancer in patients with neurogenic bladder: a systematic review. Neurourol Urodyn. 2018;37:1386-95.

7. Liu B, Welk B. Urological malignancies in neurogenic patients. Curr Opin Urol. 2020;30:501-6.

8. Böthig R, Tiburtius C, Fiebag K, Kowald B, Hirschfeld S, Thietje R, et al. Traumatic spinal cord injury confers bladder cancer risk to patients managed without permanent urinary catheterization: lessons from a comparison of clinical data with the national database. World J Urol. 2020;38:2827-34.

9. Nahm LS, Chen Y, DeVivo MJ, Lloyd LK. Bladder cancer mortality after spinal cord injury over 4 decades. J Urol. 2015;193:1923-8.

10. Cameron AP, Rodriguez GM, Schomer KG. Systematic review of urological followup after spinal cord injury. J Urol. 2012;187:391-7.

11. Elliott SP. Screening for bladder cancer in individuals with spinal cord injury. J Urol. 2015;193:1880-1.

12. Kirshblum SC, Burns SP, Biering-Sorensen F, Donovan W, Graves DE, Jha A, et al. International standards for neurological classification of spinal cord injury (revised 2011). J Spinal Cord Med. 2011;34:535-46.

13. Biering-Sørensen F, DeVivo MJ, Charlifue S, Chen Y, New PW, Noonan V, et al. International spinal cord injury core data set (version 2.0) - including standardization of reporting. Spinal Cord. 2017;55:759-64.
14. Humphrey PA, Moch H, Cubilla AL, Ulbright TM, Reuter VE. The 2016 WHO classification of tumours of the urinary system and male genital organs - part $b$ : prostate and bladder tumours. Eur Urol. 2016;70:106-19.

15. Böthig R, Kurze I, Fiebag K, Kaufmann A, Schöps W, Kadhum T, et al. Clinical characteristics of bladder cancer in patients with spinal cord injury: the experience from a single centre. Int Urol Nephrol. 2017;49:983-94.

16. Ho CH, Sung KC, Lim SW, Liao CH, Liang FW, Wang JJ, et al. Chronic indwelling urinary catheter increase the risk of bladder cancer, even in patients without spinal cord injury. Medicine (Baltimore). 2015;94:e1736.

17. Hollingsworth JM, Rogers MA, Krein SL, Hickner A, Kuhn L, Cheng A, et al. Determining the noninfectious complications of indwelling urethral catheters: a systematic review and meta-analysis. Ann Intern Med. 2013;159:401-10.

18. Groah SL, Weitzenkamp DA, Lammertse DP, Whiteneck GG, Lezotte DC, Hamman RF. Excess risk of bladder cancer in spinal cord injury: Evidence for an association between indwelling catheter use and bladder cancer. Arch Phys Med Rehab. 2002;83:346-51.

19. Vereczkey ZA, Schmeidler J, Binard JE, Bauman WA. Bladder cancer risk in patients with spinal cord injury. J Spinal Cord Med. 1998;21:230-9.

20. Kalisvaart JF, Katsumi HK, Ronningen LD, Hovey RM. Bladder cancer in spinal cord injury patients. Spinal Cord. 2010;48:257-61.

21. Böthig R, Golka K, Tiburtius C, Balzer O, Kowald B, Hirschfeld S, et al. Incidental bladder cancer at initial urological workup of spinal cord injury patients. Spinal Cord Ser Cases. 2020;29(6):55.

22. Alimi Q, Hascoet J, Manunta A, Kammerer-Jacquet SF, Verhoest G, Brochard C, et al. Reliability of urinary cytology and cystoscopy for the screening and diagnosis of bladder cancer in patients with neurogenic bladder: a systematic review. Neurourol Urodyn. 2018;37:916-25.

23. Blok B (Chair), Castro-Diaz D, Del Popolo G, Groen J, Hamid R, Karsenty G, et al. EAU Guideline Neuro-urology. 2019. https://uroweb.org/guideline/neurourology/ (Last accessed 15 March 2021).

24. Consortium for Spinal Cord Medicine. Bladder management for adults with spinal cord injury: a clinical practice guideline for health-care providers. J Spinal Cord Med. 2006;29(5):527-73.

\section{AUTHOR CONTRIBUTIONS}

$\mathrm{RB}$ had full access to all the data in the study and takes responsibility for the integrity of the data and the accuracy of the data analysis. Study concept and design: RB, RT, KG. Acquisition of data: RB, KF, OB, CT. Analysis and interpretation of data: RB, BK, KG. Drafting of the manuscript: RB, TK, KG. Critical revision of the manuscript for important intellectual content and proof of the final version: $B K, K F, O B, C T, R T, T K$, KG. Obtaining funding: None. Statistical analysis: BK, RB. Administrative, technical, or material support: RT. Supervision: RT, TK, KG.

\section{ETHICAL APPROVAL}

We certify that all applicable institutional and governmental regulations concerning the ethical use of human volunteers/animals were followed during the course of this research.

\section{COMPETING INTERESTS}

The authors declare no competing interests.

\section{ADDITIONAL INFORMATION}

Supplementary information The online version contains supplementary material available at https://doi.org/10.1038/s41393-021-00651-3.

Correspondence and requests for materials should be addressed to R.B.

Reprints and permission information is available at http://www.nature.com/ reprints

Publisher's note Springer Nature remains neutral with regard to jurisdictional claims in published maps and institutional affiliations. 
GERMAN-SPEAKING MEDICAL SCI SOCIETY (DMGP) BLADDER CANCER EXTENDED WORKING GROUP

Almuth Angermund ${ }^{6}$, Ralf Böthig ${ }^{1}{ }^{1 凶}{ }^{凶}$, Jörn Bremer ${ }^{7}$, Johann Ebermayer ${ }^{8}$, Ronen Elishar ${ }^{9}$, Thomas Jud ${ }^{10}$, Olaf Jungmann ${ }^{11}$, Albert Kaufmann ${ }^{12}$, Ruth Kirschner-Hermanns ${ }^{13}$, Jens-Peter Klask ${ }^{14}$, Burkhard Koll ${ }^{15}$, Martin Koser ${ }^{16}$, Michael Kowollik ${ }^{13}$, Ines Kurze ${ }^{17}$, Johannes Kutzenberger $^{18}$, Isabel Märk ${ }^{19}$, Sandra Möhr ${ }^{20}$, Nicolette Münstermann ${ }^{21}$, Marcus Nehiba ${ }^{18}$, Christos Pelekanos $^{22}$, Jana Pretzer ${ }^{23}$, Andreas Redecker ${ }^{24}$, Oliver Schindler ${ }^{25}$, Rebecca Schober ${ }^{26}$, Wolfgang Schöps ${ }^{27}$, Irina Soljanik ${ }^{28}$, Ulrike Steude ${ }^{29}$, Burkhard Ubrig ${ }^{30}$, Will Vance $^{31}$, Andreas Wolff ${ }^{29}$, Jens Wöllner ${ }^{32}$ and Franko Zepke ${ }^{18}$

${ }^{6}$ Center for Neuro-Urology, Schön Klinik Vogtareuth, Germany. ${ }^{7}$ Centre for Spinal Cord Injuries, BDH-Klinik Greifswald, Greifswald, Germany. ${ }^{8}$ Department of Urology, Klinik Bavaria, Kreischa, Germany. ${ }^{9}$ Spinal Cord Injury Center, Bayreuth, Germany. ${ }^{10}$ AUVA Center for Rehabilitation, Bad Häring, Austria. ${ }^{11}$ Department of Urology, St. Hildegardis Krankenhaus, Köln, Germany. ${ }^{12}$ Department of Neuro-Urology, Kliniken Maria Hilf GmbH, Mönchengladbach, Germany. ${ }^{13}$ Neurological Rehabilitation Centre Godeshöhe, BonnBad Godesberg, Germany. ${ }^{14}$ BG Trauma Hospital Duisburg, Duisburg, Germany. ${ }^{15}$ Department of Urology, Gemeinschaftskrankenhaus Herdecke, Herdecke, Germany. ${ }^{16}$ Department of Urology, Hospital Ludwigshafen, Ludwigshafen, Germany. ${ }^{17}$ Centre for Spinal Cord Injuries, Department of Paraplegiology and Neuro-Urology, Zentralklinik Bad Berka, Bad Berka, Germany. ${ }^{18}$ Department of Neuro-Urology, Werner-Wicker-Klinik, Bad Wildungen-Reinhardhausen, Germany. ${ }^{19}$ Department of Urology, AUVA Center for Rehabilitation Weißer Hof, Wien, Austria. ${ }^{20}$ Clinic of Neurorehabilitation and Paraplegiology, REHAB Basel, Basel, Switzerland. ${ }^{21}$ Division of Neuro-Urology, Marien Hospital Herne, Ruhr University Bochum, Herne, Germany. ${ }^{22}$ Department of Urology, University Hospital Frankfurt, Frankfurt am Main, Germany. ${ }^{23}$ Department of Urology and Neuro-Urology, BG Trauma Hospital Berlin, Berlin, Germany. ${ }^{24}$ Department of Neuro-Urology, BG Klinikum Bergmannstrost Halle, Halle, Germany. ${ }^{25}$ Department of Urology, University of Ulm, Ulm, Germany. ${ }^{26}$ Department of Urology, AUVA Center for Rehabilitation, Tobelbad, Austria. ${ }^{27}$ Urological Practice, Sankt Augustin, Germany. ${ }^{28}$ Department of Neuro-Urology, Spinal Cord Injury Center, Heidelberg University Hospital, Heidelberg, Germany. ${ }^{29}$ Department of Urology, BG Unfallklinik Murnau, Murnau, Germany. ${ }^{30}$ Department of Urology, Augusta Kliniken Bochum Hattingen, Bochum, Germany. ${ }^{31}$ Department of Urology, Kliniken Beelitz GmbH, Beelitz-Heilstätten, Beelitz, Germany. ${ }^{32}$ Department of Neuro-Urology, Swiss Paraplegic Centre, Nottwil, Switzerland. 